\title{
Study on the Current Situation and Development of English Interpretation Teaching in College
}

\author{
$\mathrm{Bo} \mathrm{Ni}$ \\ School of Foreign Studies, Xi'an University ,710065
}

Keywords: College English; Interpretation; Teaching

\begin{abstract}
With the comprehensive and all-round development of economy in China, foreign economic and cultural exchanges have become increasingly frequent. Nowadays, countries all over the world are getting closer when globalization and integration become dominant main stream. English as an international language plays a pivotal role in foreign exchange. Interpreting as an important part of English application is an indispensable part of communication. In the meanwhile, we need more and more qualified English interpretation talents. How to cultivate English interpretation talents with high quality is an urgent and realistic problem that every educator has to face. This paper is going to give a brief overview of the present situation of English interpretation teaching and then analyze its development path as well as solutions.

Globalization and integration are the main development directions nowadays. In recent decades, the economy and trade continue to grow and the society needs soaring interpretation talents. Interpreting is a kind of language activity to orally express the ideas, emotions and connotation in another language in certain situations which can be deemed as a process to comprehensively apply the knowledge as well as skills of viewing, listening and speaking. With the advancement of China's modern cause, the demands of society for interpreting talents are increasing, and the number is soaring.

On the one hand, our society needs more and more interpreting talents, on the one hand, there are many deficiencies and bottlenecks in the interpretation education. How to effectively solve the problems encountered in reality and develop specific measures to ensure the sound and health development of interpretation work in college and cultivate talents adapted to the society are real and difficult problems.
\end{abstract}

\section{The Importance of College English Interpretation Teaching}

Due to the history and the teaching system of our country, interpreting has not been paid attention to in a very long period. In the context of advocating quality education, interpretation is clearly a very important part of strengthening English quality.

Language is the way for people to carry out communication. However, there are diverse regions and countries so the language is diverse. English as an international common language plays an irreplaceable role in cultural exchange. Correspondingly, English interpretation becomes an essential communication tool. Interpreters are able to quickly express the ideas of another language so as to achieve the purpose of information exchange.

Many colleges take English Interpretation as a compulsory course, and teachers mostly teach basic theories and interpretation skills in class, which help to lay a solid foundation for future study. However, from the perspective of social needs, the interpretation still lags behind. Since the reform and opening up, China has made great progress in economy, society development and culture. In addition, since most of the countries began to carry out international cooperation, tourism, investment, international lectures are developing while there is still a big shortage of interpretation talents. The bridging role interpretation plays in communication between China and the world is obvious to all. To cultivate interpretation talents is not only related to the overall strategy of quality education in colleges but will also promote the cause of China's modernization drive. 


\section{The Meaning for Improving College English Interpretation Teaching}

Interpretation teaching is not a simple continuation of language teaching and it is of significant importance to improve college English interpretation:

\section{To further develop reform and following up}

In recent years, our achievements in reform and opening up are there for all to see. In addition, along with the continuous strengthening of China's reform and opening up, the demand for interpreting talent is bound to increase. In addition, it is necessary to cultivate talents who can satisfy the needs, improve the defects of college English interpretation so as to conform to the actual requirements and needs of China's reform and opening up.

\section{Big improvement space for college English interpretation teaching}

It is undeniable that, after continuous development and perfection, the interpreting teaching in our country has made certain achievements, but the deficiencies and contradictions are still very prominent. There is still a lot of room for improvement for it. From a macro point of view, there are multiple defects in teaching ideas, curriculum, teacher equipment, teaching methods and these shortcomings have seriously hindered the cultivation of interpreting talents in colleges.

\section{The quality of interpretation talents in college needs improvement}

The main role of English interpreters is to serve the needs of the community, which is the basis of all personnel training. But there are only few people who can undertake the role while taking the cultivation results into consideration. That is to say, a considerable part of the interpreters cannot do their jobs. The low quality of interpreters does not only cause the waste of teaching resources but also hinder the implementation of work.

\section{Main Problems of English Interpretation Teaching in Colleges}

In recent years, many educators have carefully studied the problems existing in the teaching of English interpretation and carried out a careful analysis and summary. Moreover, lots of people have also improved the problems found in educational practice. In general, we have achieved a good result. However, due to the relatively blocked educational system in colleges, the English interpretation reform is still stalled.

At present, the main problems for college English interpretation education show as follows:

\section{The Faculties and Equipment are in Shortage}

At present, the investment on college interpretation and faculties are relatively insufficient. What's more, there is a big difference in terms of basic knowledge reserve, teaching concept update, academic background and training comparing to other countries. Many colleges arbitrarily assign English teaching instructors as interpreting teachers, who cannot play their roles because they are not equipped with sufficient theoretical knowledge. In addition, lots of schools have a vague understanding of interpretation teaching and continue to decrease the importance of it. In their mind, students' interpretation ability will naturally be improved if they can master the theoretical knowledge. Furthermore, there are still some schools do not attach importance to the cultivation of students' practical ability, but only focus on theoretical education. As a result, many students only know theoretical knowledge.

Qualified English interpreters play a very important role in improving teaching quality, so colleges should vigorously strengthen the training of English interpretation teachers. In the training of those teachers, we should focus on their English application ability and overall quality improvement. Moreover, they should have more opportunities to contact the internal market and society so as to well understand the market requirement and development change. In this way, teachers are engaged in the market and can take the initiative to research and explore new ideas and philosophy.

\section{Rigid Teaching Methods}

For many English interpreters, teachers are not able to use flexible teaching methods because of lots of limitations and therefore they are unable to create a good academic atmosphere for students. Being exposed to traditional teaching style, teachers can only do extensive reading and focus on the 
theoretical knowledge but ignore the practical ability cultivation. As a result, it is difficult for students to feel the real language environment. Interpretation itself is a very practical subject, the improvement of students' ability should mainly come from practice. However, this kind of teaching style cannot meet the needs of learning. As time passes by, students will lose interest and it is very unfavorable for students to develop further.

Judging from the current college English interpretation teaching in China, lots of schools still adopt a traditional teaching mode. In the classroom, teachers teach while students record and their relation is typical subordination and their passion cannot be ignited. In addition, lots of colleges do not invest enough on new technology and they still use blackboard chalk. The development of multi-media as well as network technology should firstly be demonstrated in education system but unfortunately, the interactive communication means is not as popular as we expect and needs to be promoted.

\section{The Guideline and Teaching Material Construction needs to be Strengthened}

Compared with the increasing needs of English interpreting talents, colleges have not set relevant plans. We don't have relevant guidelines, limitations and regulations as well as an evaluation system. At present, many college can only adopt English syllabus to organize English teaching, however they are not similar. As a result, English interpretation teaching cannot clear the teaching targets and tasks and will definitely lead to the low efficiency. In terms of materials, lots of them are old, which is also an important factor to affect the talents cultivation. Even though there are lots of books related to interpretation, they still pay attention to traditional theoretical teaching as well as the language transfer. So, the theory of interpretation is far disconnected with practice. These materials focus on logical thinking training and are confined to certain experience, which are not systematic and scientific. So, it is very difficult to achieve unprecedented results. At present, the teaching materials used in English interpreting are monotonous, which are in shortage of novelty, specialty and pertinence.

\section{Teaching Contents Ignore Culture Introduction}

Language and culture are inseparable. There is a point which we have been ignoring in English interpretation: culture introduction. English interpretation, as an important part of English teaching cannot be divorced from English culture. As the famous linguist Rado said: we cannot teach a language well if we don't understand its culture. Language is a part of culture and therefore, we cannot truly understand a language if we don't know the rules and modes of the culture. Language is a part of culture and culture is also a part of language, they are inseparable and it will be nonsense if they are separated. So, being divorced from culture is an obvious shortage of English interpretation education.

\section{Main Solutions to Improve the Quality of English Interpretation Teaching in Colleges}

Overall, there are lots of unsatisfactory points in English interpretation and it is very urgent to well perform the work. As far as the author is concerned, it can be improved from the following aspects:

\section{Create High-Quality Faculties for English Interpretation Teaching}

In recent years, reflective teaching has been popular in foreign interpretation teaching reform. Reflective teaching, as a totally new interpretation teaching model, its connotation is to take teaching content and teaching methods as traditional teaching forms and then change a development of direction to faculty cultivation and professional development. Concerning this point, we should guide teachers to take professional knowledge and teaching experience as the fundamental point and at the same time focus on the ability cultivation to find problems, analyze problems, solve problems so as to improve their teaching ability as well as practical ability. Interpretation as a subject with a very high requirement is closely related to culture, history, linguistics, and art. English interpretation teachers should also improve themselves in terms of psychological quality, language level, the scope of knowledge, flexible application capacity, responsiveness, etc. so as to strive to improve their interpretation skills. 


\section{Try Unremitting Efforts to Improve the Teaching Materials}

In interpreting teaching, the basic requirement is to improve their basic foundation. Therefore, we should try to cultivate students' ability to apply knowledge into reality and encourage them to apply knowledge in daily work, life and study. At the same time, they should also pay attention to improve their ability to be adapted to the society and strengthen their competence. By the way, the selection of teaching materials should be adapted to the targets of cultivating talents, which should also be in accordance with the reality of schools and the development trend of our society. Only when we meet the requirements can we help to enrich the theoretical knowledge of students and broaden their horizon to encourage them take the initiative to study.

\section{Make a Scientific Outline and Regulate the Course Setting}

The development of the syllabus should be scientific, practical with proper setting. In addition, we have to clear the teaching purposes, teaching content, focus, difficulty, inspection methods and inspection standards so as to make sure we have combined qualitative and quantitative analysis. Once we have a clear syllabus, we will know what kind of aspects can we improve and teachers will properly prepare a schedule with proper materials so as to achieve the teaching goal. In terms of curriculum setting, we should make an orderly, proper, standard and systematic plan to guarantee that teachers can carry out their teaching plan and students at the same time are granted enough time to polish themselves.

\section{Try tireless Efforts to Enrich their Professional Knowledge}

Interpretation is a systematic and mental work. Interpretation requires a very high quality of professional knowledge and diverse knowledge. The reserve of professional knowledge is an indispensable prerequisite for students to do interpreting, including politics, finance, law, education, medicine and so on. Only when students have a wealth of expertise, can they easily and freely deal with all types of interpretation work.

\section{Improve students' Consciousness to Improve Interpretation Skills}

The cultivation of interpreting skills cannot happen overnight. However, we should develop students' awareness of improving their interpretation skills. As a basic course, one of the functions of interpretation is to cultivate their habits to take the initiative to improve themselves. In addition, we should change their old traditions and cultivate their diligent and scientific habits of learning.

\section{Strengthen the Construction of the Evaluation System for Interpretation}

The sound development of everything cannot be separated from the construction of evaluation system, which plays a pivotal role in smoothly carrying out interpretation education. This kind of evaluation system can be interim or long term. Based on the interim evaluation system, we can assess the learning result in certain period and find out the shortcomings. This evaluation should be two-sided while both teachers and students can comment on each other. In addition, the evaluation should also comprehensively take everything into consideration so as to effectively guide the education.

\section{Conclusion}

Colleges, as the main base to cultivate high-quality talents shoulder the mission to cultivate talents for modernization. We should fully understand the importance of English interpreting and teaching reform in improving the training of talents, and try to improve our professional knowledge and skills, actively explore the ways of teaching reform and continuously improve their academic literacy. Only in this way, can we fundamentally improve the overall quality of English interpretation and cultivate talents who can satisfy the development of our economy and society.

\section{References}

[1] Zhong Weihe. Knowledge structure of interpreters and course setting of interpretation course[J]. Chinese Translators Journal, 2003(4): $63 \sim 65$ 
[2] Huang Jianfeng, Lixue. Interpretation and the arts of speaking [J]. Chinese Translators Journal, 2007

[3] Liu Miqing. Contemporary Translation Theories[M]Beijing: the External Translation Press of China, 1999

[4] Bao Gang. An overview of interpretation theories[M]. Beijing: Tourism Education Press, 1998

[5] Bao Chuanyun, The positioning and teaching of college English interpretation [J], Chinese Translators Journal: 2004(5).

[6] Sailaisike. An introduction to translation Beijing Language and Culture University Press, 1992

[7] Liu Miqing. Contemporary Translation Theories[M]Beijing: the External Translation Press of China, 1999, 254

[8] Liu Heping. Interpretation skills- though science and interpretation deduction method[M] China Translation and Publishing Corporation, 2001 (7)

[9] The Steering Committee of college foreign language teaching English group - The syllabus for English majors in colleges[M] . Beijng: Foreign Language Teaching and Research Press, 2000

[10] Wang Xuewen. Business Interpretation course book, China International Business and Economics Press, 1993.7

[11]Zhong Weihe. Principles and Methodology for Interpreting Training[J] Journal of Guangdong University of Foreign Studies, 2007 (5), 5-7

[12] Liu Heping. Interpreting Skills-The science of thinking and reasoning method of interpretation[M]. China Translation and Publishing Corporation, 2001 